\title{
Kun Kekkonen sivalsi... Kekkonen huumorin taitajana
}

Kekkosella oli monellakin tavalla erikoinen ja erityinen huumorintaju. Hän oli ennen kaikkea sutkautusten ja tilannekomiikan ystävä. Tämän kaltaisen huumorin harrastaja ei etukäteen paljasta kertovansa vitsiä ja pakota läsnäolijoita kuuntelemaan ulkoa opeteltuja pitkiä johdantoja, jotka ovat usein jo vanhentuneita tai yleisesti tunnettuja. Sen sijaan sutkautusten ja tilannekomiikan ystävä tarttuu ohikiitävän hetken mahdollisuuksiin, tilanteen tarjoamiin lavasteisiin, toisen tekemään virheeseen ja niin edelleen. Tällöin ironia viiltää.

Juuri edellisen kaltaisessa ironian ja sarkasmin miekan käytössä Kekkonen oli ehdoton mestari. Hän viilsi hyytävän suoraan vastustajan heikkoihin kohtiin. Ironian säilä oli hänellä sekä poliittisessa että ihmissuhdekäytössä. Kekkonen oli jo nuorena kaveripiirin parhaita" pilkkakirveitä". Sananheitto oli tuossa piirissä lähellä nuoruuden käsirysyä. Urholla sanottiin olevan "kieli kuin puukko". Hänen luonteestaan kertoo kouluajan kutsumanimi "Känä".

Kekkosen sutkautuksiin liittyi useimmiten naljaileva tyyli. Tällaista huumoria voikin kuvata "naljailevaksi hurttihuumoriksi". Jokainen Suomen armeijan läpikäynyt on joutunut kokemaan sen. Toiset pitävät tämän kaltaisesta huumorista, toiset eivät. Parhaimmillaan tällainen huumori oli 1920-luvulla - juuri siinä ensimmäisen tasavallan nuorten, lahjakkaiden ja eteenpäin pyrkivien miesten toveripiirissä, johon Kekkonenkin lukeutui.

Ongelmalliseksi hurtti huumori ja piikittely muodostuvat silloin, kun niiden harrastaja on ylivertaisessa asemassa. Kohde ei uskalla antaa takaisin samalla mitalla. Jotkut kohteeksi joutuneet loukkaantuvat sydänjuuriaan myöten ja kokevat naljailun sydämen sivistymättömyydeksi ja moukkamaisuudeksi. Näin kävi esimerkiksi Kekkosen naljaillessa Arimo Raesteelle. Asiasta voi varmistua lukemalla hänen muuten huumorilla höystetyt muistelmansa.

Voisikin sanoa, että jossain määrin aika ajoi Kekkosen huumorin hurttipuolen ohitse. Se miekka, jota oli sallittua käyttää nuorten miesten ja myöhemmin tasavertaisten poliitikkojen piirissä, kasvoi vuosien myötä moukariksi, joka oli kohtuuton ase. Valtansa huipulla olevan presidentin edessä uhri oli useimmiten voimaton. Kekkosen sivallus oli kuin karhun taputus. Vain harva osasi ja rohkeni vastata samaan tyyliin. Max Jakobson onkin verrannut osuvasti Kekkosta leijonankesyttäjään, jonka leijonat olivat loppuneet.

Kekkonen ei itse tätä asemaansa ja sen seurauksia täysin mieltänyt. Kuvaavaa onkin hänen valittelunsa eräälle suurlähettiläälle. Kekkosen mielestä huumori ja hyvän sutkautustaidon omaavat ihmiset olivat kuolemassa sukupuuttoon. Väinö Leskinen miekkaili sanan säilällä Kekkosen kanssa tunnettuun kääntymykseensä asti. Ilmari Turja oli niitä harvoja pitkäaikaisia ystäviä, joka osasi ja jaksoi miekkailla Kekkosen kanssa loppuun asti. 


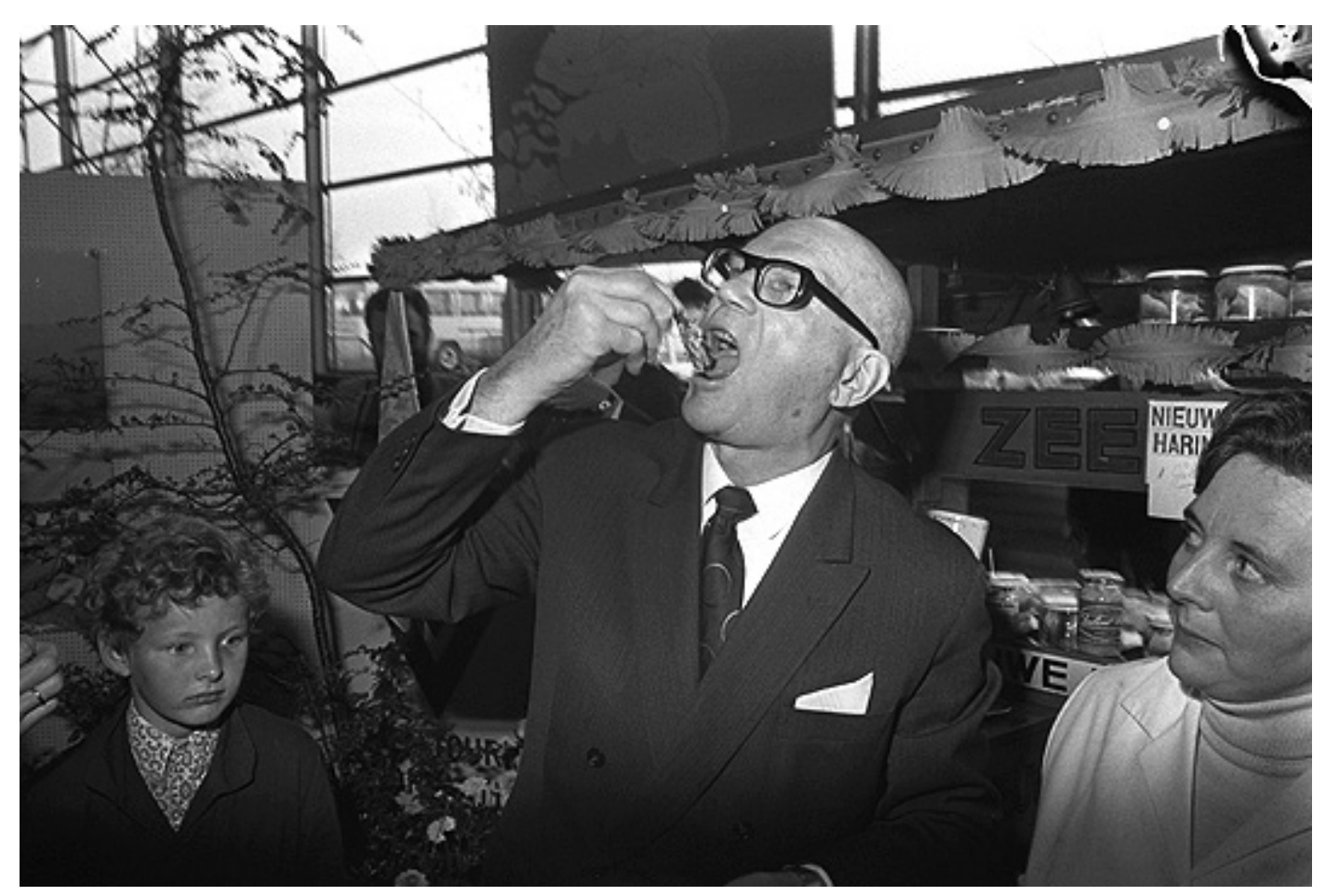

Kekkosen piikittelevä huumori oli vastustajille paikoin suolaista kuin silli. Kuvassa Kekkonen itse testaa alankomaista silliä valtiovierailullaan 1972. Kuva: @ Rob Mieremet (ANEFO), Wikimedia Commons, https://commons.wikimedia.org/wiki/File:KekkonenHerring1972.jpg.

Eräs tilannekomiikan ja naljailevan ironian käytön huonoja puolia on, ettei tämän lajin huumoria pysty varsinaisesti toistamaan. Sutkautukset ovat sitoutuneet liikaa ohikiitävään hetkeen ja sen mahdollisuuksiin. Omasta hetkestään irrotettuna ironinen tilannekomiikka menettää mehunsa. Toistettuina ja toisessa ajassa siinä on vaikeaa nähdä mitään naurettavaa.

\section{Lyhyeen lopettamisen taito}

Kekkonen osasi lopettaa tietyn asian käsittelyn kertaheitolla ironian miekan sivalluksella. Suomen Sofian suurlähetystössä oli väärinkäytetty alkoholia, ja asiasta tuli presidentille useampia juorutasoisia valituksia. Kekkonen, joka ei itsekään sylkenyt lasiin, vastasi valtiosihteerille:

Kuitenkin on asia niin, että mies, joka ei tee muuta virhettä - tai ei tee muuta ylimalkaankaan - kuin että kun on humalatilassa, on humalassa, tekee maalle vähemmän vahinkoa kuin mies, joka selvin päin tekee tyhmyyksiä.

Sekä juoruilu että juopottelu loppuivat kuin veitsellä leikaten!

Suurlähettiläs Asko Ivalon terveys oli ruvennut horjumaan viimeisinä vuosina ennen eläkkeelle siirtymistä. Hänen vaimonsa, kuvanveistäjä Emil Wikströmin tytär Mielikki Ivalo oli tunnetusti "hankala naisihminen"; asiasta voi varmistua lukemalla hänen muistelmansa Vanavedessä. Ivalo komennettiin Intiaan suurlähettilääksi. Mielikki ei yhtään pitänyt asiasta ja masinoi lähetystön puhumaan asiasta presidentille. Lähetystön tehtävänä oli kertoa, ettei Askon horjuva terveys kestäisi Intian komen- 
nusta. Kekkonen kuunteli lähetystön asian ja tuumi pitkään. Lopulta hän lausui: "En peru määräystä. Päinvastoin. Olen kuullut, että Intiassa lesket poltetaan roviolla!"

Kemijoki Oy:llä oli Porojärvellä Käsivarressa pieni kämppä, jossa Kekkonen kävi mielellään kalassa ja hiihtämässä. Kemijoki Oy:n toimitusjohtaja, vuorineuvos Axelsson oli mukana Porojärvellä, jossa hän ei ollut aikaisemmin käynyt. Astuttuaan kämppään vuorineuvos kysyi Kekkoselta, että "kuinkas me täällä sitten nukutaan?" Kekkonen vastasi vastakysymyksellä: "Ketkä Me?" Axelsson ymmärsikin hakea yösijan rajavartiomiesten hoteista.

\section{Vastustajan häirintä ja torjunta}

Kalevi Sorsa määritteli Kekkosen "armottomaksi, nopeaksi ja tehokkaaksi pilkkakirveeksi ja huulenheittäjäksi, joka nautti roolistaan!" Kekkonen osasikin sutkautuksillaan pysäyttää ja nolata poliittisen vastustajansa ainutlaatuisella tavalla. Usein hän iski, ennen kuin vastustaja pääsi edes kunnolla alkuun. Esittelen pari esimerkkiä.

Raoul Palmgren - kommunisti ja päätoimittaja - aloitti kiivaaksi hyökkäykseksi suunnittelemansa puheen "Meikäläisessä lehdistössä --". "Kuule!", keskeytti Kekkonen. "Tarkoitatko Sinä teikäläistä vai suomalaista lehdistöä?" Terä Palmgrenin puheesta oli kertaheitolla taitettu.

Toinen esimerkki kertoo siitä, miten Kekkonen "sanan säilällä" katkaisi Ahti Karjalaisen kuningastien vuonna 1973. Miesten välit olivat ajan myötä muuttuneet suorastaan riitaisiksi. Karjalaisen 50-vuotispäivien lähestyessä lehdistössä alkoi ilmestyä kirjoituksia, joissa korostettiin, miten miellyttävä Ahti Karjalainen oli yksityishenkilönä. Erityisesti kehuttiin hänen huumorintajuaan, joka pääsi hienosti esille Karjalaisen lähipiirissä.

Kampanja huipentui Karjalaisen juhlapäivänä Hotelli Marskissa. Laaja yleisö kuunteli kiusaantuneena mutta kohteliaasti nyökytellen huumorimies Karjalaisen ylistyksiä. Harva kuului tuohon lähipiiriin, joka olisi voinut tietää jotain asiasta. Lopulta nousi puhumaan illan päävieras, tasavallan presidentti. Jännitys väreili ilmassa. Kekkonen katsoi yleisöään, jonka tunnelman hän oli vaistonnut. "Niin!", hän aloitti hymyillen ja piti pitkän tauon. "Kyllähän meidän kuitenkin on myönnettävä, ettei Ahti mikään kuoliaaksi naurattaja ole!"

Presidentin ytimeen menevä kommentti räjäytti pankin. Keinotekoisen huumorimiehen kuvan aiheuttama kiusaantuneisuus laukesi hillittömäksi nauruksi. Yleisö hörötti suureen ääneen minuuttitolkulla. Sen jälkeen ei Karjalaisen huolella rakennetusta huumorimiesimagosta ollut käyttötavaraksi. Jotkut toimittajat muistelevat tätä hetkeä presidentinvaalien "käännekohtana".

\section{Torjunnan taito}

Hyvänkin iskun ja sutkauksen tai vaikean tilanteen voi torjua taitavalla vastaiskulla. Seuraava esimerkki kertoo tällaisesta torjunnasta. Iskijä on Kekkonen, mutta loistava torjuja on niin ikään taitava poliitikko, eduskunnan puhemies Sukselainen. Presidentin ja puhemiehen suhteet eivät olleet parhaat mahdolliset, eikä presidentti ollut kohdellut puhemiestä parhaalla mahdollisella tavalla. Vietettiin iltaa, ja paikalla oli runsaasti keskustapuolueen väkeä. Virvokkeitakin oli tarjolla, mutta tunnelma pysyi laimeana ja hapahkona. Kekkonen päätti iskeä. Hän totesi kovalla äänellä Sukselaiselle: "Sinäkin olet sellainen mies, että mitään et tekisi vaikka päälle kusisi!" "No älä kuse!", kuului Sukselaisen vastasivallus! Niille, jotka tunsivat herrojen suhteet, torjunta oli täydellinen ja vaiensi itsensä Kekkosen. 
Vanheneva mestari kykeni kääntämään heikkoudet edukseen. Kekkosen todellinen kunto oli eräänlainen valtakunnansalaisuus. Lähes kahdeksankymppisen presidentin väitettiin olevan nelikymppisen kunnossa. Hänelle oli kuitenkin tapahtunut lukuisia lipsahduksia ja haavereita, jotka puhuivat aivan toista. Presidentin sisälukuongelmaankin oli jo kiinnitetty huomiota; suorien lähetysten mies oli joutunut vuodesta 1978 turvautumaan nauhoitettuihin uudenvuodenpuheisiin. Kunto vaihteli päivittäin. Vastustajille ei kuitenkaan sopinut antaa argumentteja.

Vuonna 1979 presidentti vieraili Länsi-Saksassa. Hänen ohjelmaansa kuului pitää illallispuhe Augsburgin linnassa Bonnissa liittopresidentti Walter Scheelin johtaman arvovaltaisen isäntäjoukon läsnä ollessa. Yhtäkkiä presidentti ei kuitenkaan nähnyt lukea. Yleisö istui tulisilla hiilillä. Presidentti ei kuitenkaan menettänyt arvokkuuttaan eikä konseptejaan. Hän kysyi saksaksi, oliko se Goethe, joka lausui kuuluisat sanat "Mehr Licht!", enemmän valoa! Mehr Licht -tokaisu osoitti loistavaa tyylitajua. Se käänsi huomion pois ongelmasta ja vaiensi mahdolliset epäilyt. Kotona lehdistö ylisti presidentin hoitaneen "valtiovierailun kiperimmän tilanteen huippuhienosti".

\section{Vanheneva presidentti}

Vanhenevan presidentin voi myös väittää menettäneen arvostelukykyään. Sylvi Kekkosen myötä presidentti menetti parhaan tyylitaiturinsa ja sensuroijansa. Sarkastiset ja viiltävät kirjeet olivat Kekkoselle vallan väline. Niillä hän tavoitti ja lannisti töpeksijät ja vastustajat. Tehostaakseen kirjeidensä vaikutusta Kekkonen saattoi antaa ne julki. Mutta vasta Sylvi Kekkosen kuoleman jälkeen presidentti turvautui laajamittaiseen julkaisemiseen. Näin syntyivät Kirjeitä myllystäni I ja II. Kekkonen kuvasi itse, millaisesta myllystä oli kyse. Se oli "pauhaava, ryskivä, jyskivä ja jauhava".

Moni virkamies koki tulleensa syvästi loukatuksi. Eräät totesivat myllykirjeiden julkaisemisen vapauttaneen heidät uskollisuuden velvoitteestaan presidentille ja ulkoministeriölle. Myös moni vanha ystävyyssuhde katkesi. Kuvaava esimerkki on kuulantyöntäjä Ville Pörhölän saama kirje. Ville oli arvostellut Kekkosta ja hänen ulkopolitiikkaansa. Presidentti paheksui sitä, että hänen vanha urheilutoverinsa luuli ulkopolitiikassa olevansa "yhtä suuri asiantuntija kuin aikoinaan moukarinheitossa kahdella pyöräytyksellä". Presidentti lopetti kirjeensä Pörhölälle vertaukseen:

Joskus ennen - kuten muistat - sanottiin, että Niittymaalta on mennyt pää sekaisin, kun on pyörinyt kiekonheitossa aina yhtäälle päin. Moukarilla näyttää olevan iän kanssa yhtä paha vaikutus.

\section{Vaikenemisen vaikea taito}

Ironia ja iva ovat äärimmäisiä aseita. Politiikassa ne ovat eräänlaisia tuomiopäivän aseita, joilla vaiennetaan vastustaja yhdellä iskulla. Henkiin jäädessään iskun kohteesta tulee kuitenkin helposti vaarallinen vihamies. Siksi ivan käyttö on niin sanotusti taitolaji. Käyttäjältä vaaditaan poliittista silmää, sillä väärin käytettynä iva ja ironia kääntyvät käyttäjäänsä vastaan.

Kekkonen tiesi tarkkaan, milloin säilä oli paras jättää huotraansa. Tässä piileekin ero tavallisen "pilkkakirveen" ja todellisen mestarin välillä. Kekkonen oli sopeutunut toisen maailmansodan jälkeen muuttuneisiin olosuhteisiin myös tällä tasolla. Pitkäaikainen pääministeri Kalevi Sorsa todistaakin muistelmissaan:

Hän [Kekkonen] ei koskaan sanonut arvostelevaa sanaakaan Neuvostoliitosta, ei edes luotetussa suomalaisessa keskustelupiirissä. Vaikka hän oli nopea ja armoton pilkka- 
kirves ja huulenheittäjä - ja nautti siitä - hän ei koskaan kuulteni livahduttanut kompaa, jonka kärki olisi sisältänyt kriittisen huomion tai arvion suuresta naapurista. Hän oli alituisesti valppaasti varpaillaan.

Suurlähettiläs Jorma Vanamo muisteli Kekkosen sanoja ottaessaan vastaan Moskovan suurlähettilään tehtävät:

Älä milloinkaan ja missään arvostele Neuvostoliittoa tai neuvostoliittolaisia. Se kiertyy aina jotain kautta heidän korviinsa ja he eivät sitä ymmärrä, eivät silloinkaan kun se on sanottu huumorilla!

Mestari tunnetaan siitä, että hän osaa laskea sivalluksensa vaikutuksen pitkälle eteenpäin - hieman samaan tapaan kuin shakinpelaaja siirtonsa vaikutukset jatkopeliin. Joskus vaikeneminen on kultaa! Mestari tietää myös, milloin hän on saanut kuolettavan piston, eikä yritä rimpuilla vastaan.

Ilmari Turja - tuo tietäjä iänikuinen ja Kekkosen "miekkailuvastustaja" loppuun asti - oli lähdössä vaimoineen Turkkiin. Turja kertoi käyvänsä myös Efesoksen rauniokaupungissa. Kekkonen muisteli Paavalinkin käyneen Efesoksessa. Presidentti jatkoi: "Mitä se Paavali siellä Efesoksessa tekikään ja viipyikin niin kauan?" Turja murjaisi: "Niitä se, Myllykirje-hommia!" Se pisto tiesi paikkansa, eikä Kekkonen yrittänytkään enää vastaiskua. Totesi vain: "Tousché!"

\section{Itseironia}

Vaikenemisen lisäksi itseironia kuului mestarin arsenaaliin. Tappion hetkellä ja ahtaalle ajettuna Kekkonen usein tokaisi: "Tappaa eivät tohdi ja tiineeksi eivät saa!" Nauru itselleen vaati aikaa. Kekkonen kykeni myös siihen - tosin viiveellä. Usein kävi niin, että presidentti ensin "kirosi kuin turkkilainen", kuten Risto Hyvärinen asian ilmaisi. Myöhemmin asialle kuitenkin naurettiin makeasti. Seuraava kertomus viestii itseironian viiveestä.

Kekkosen ja pilapiirtäjä Kari Suomalaisen voi sanoa eläneen vuosikausia symbioottisessa suhteessa: toinen piirsi ja toinen antoi aiheet - kummankin yhteiseksi eduksi ja hyödyksi. Kekkonen leikkeli Karin piirroksia ja nauroi niille salaa, joskus kiukunkin seasta:

Elettiin noottikriisin aikaa. Kari piirsi Helsingin Sanomiin nootin tapahtumiin liittyvän pilakuvan. Presidentti närkästyi kuvasta pahanpäiväisesti. Aamukahvi oli lopullisesti ja kertakaikkisesti pilalla. Kari ei enää erottanut hävyttömyyttä huumorista. Jotain oli tehtävä ja heti! Adjutantti pantiinkin asialle.

Vielä samana iltana adjutantti soitti Karille ja totesi presidentin haluavan tietää, missä

Karin käsityksen mukaan kulkee huumorin ja hävyttömyyden välinen raja.

"Rajajoella!" vastasi Kari ja sulki puhelimen.

Kun presidentti kuuli vastauksen, hän kimpaantui Karin röyhkeydestä ja kirosi hänet alimpaan. Myöhemmin Kekkonen kuitenkin palasi usein Karin sivallukseen, mikä osoittaa syvyyden, jolla isku oli viiltänyt. Hän saattoi vuosia myöhemmin pyytää kertomaan "taas sen Kari-jutun". Ja sitten naurettiin! 
$103 \cdot$ LÄHIKUVA • 2/2016

\section{Tutkimusaineisto}

\section{Arkistot}

Tasavallan Presidentin Arkistosäätiö, Orimattila

Urho Kekkosen arkisto

UKA 1 - Presidentin kansalaiskirjeenvaihto

UKK:n päiväkirjat 1958-1981

UKK:n vuosikirjat 1958-1975

Jouko Loikkasen arkisto

Jouko Loikkasen päiväkirjat 1961-1970

\section{Haastattelut}

Kirjoittaja on tehnyt haastattelut Ulkoasiainhallinnon historian kirjoittamisen yhteydessä.

Hallama, Jaakko (7.1.1993)

Hyvärinen, Risto (2.9.1992 \& 31.8.1995)

Jacobson, Max (24.2.1994)

Karjalainen, Ahti (11.10.1989 \& 18.10.1989 \& 18.1.1990)

Levo, Urpo (21.1.1994 \& 21.11.1995)

Mattila, Olavi J. (20.8.1992)

Pastinen, Ilkka (6.6.1996 \& 16.8.2004)

Seppälä, R. R. (27.10.1992)

Sorsa, Kalevi (17.11.2000)

Söderman, Tom (14.4.1994 \& 12.10.1994)

Vanamo, Jorma (2.9.1990 \& 18.10.1994)

Virolainen, Johannes (11.12.1992) 